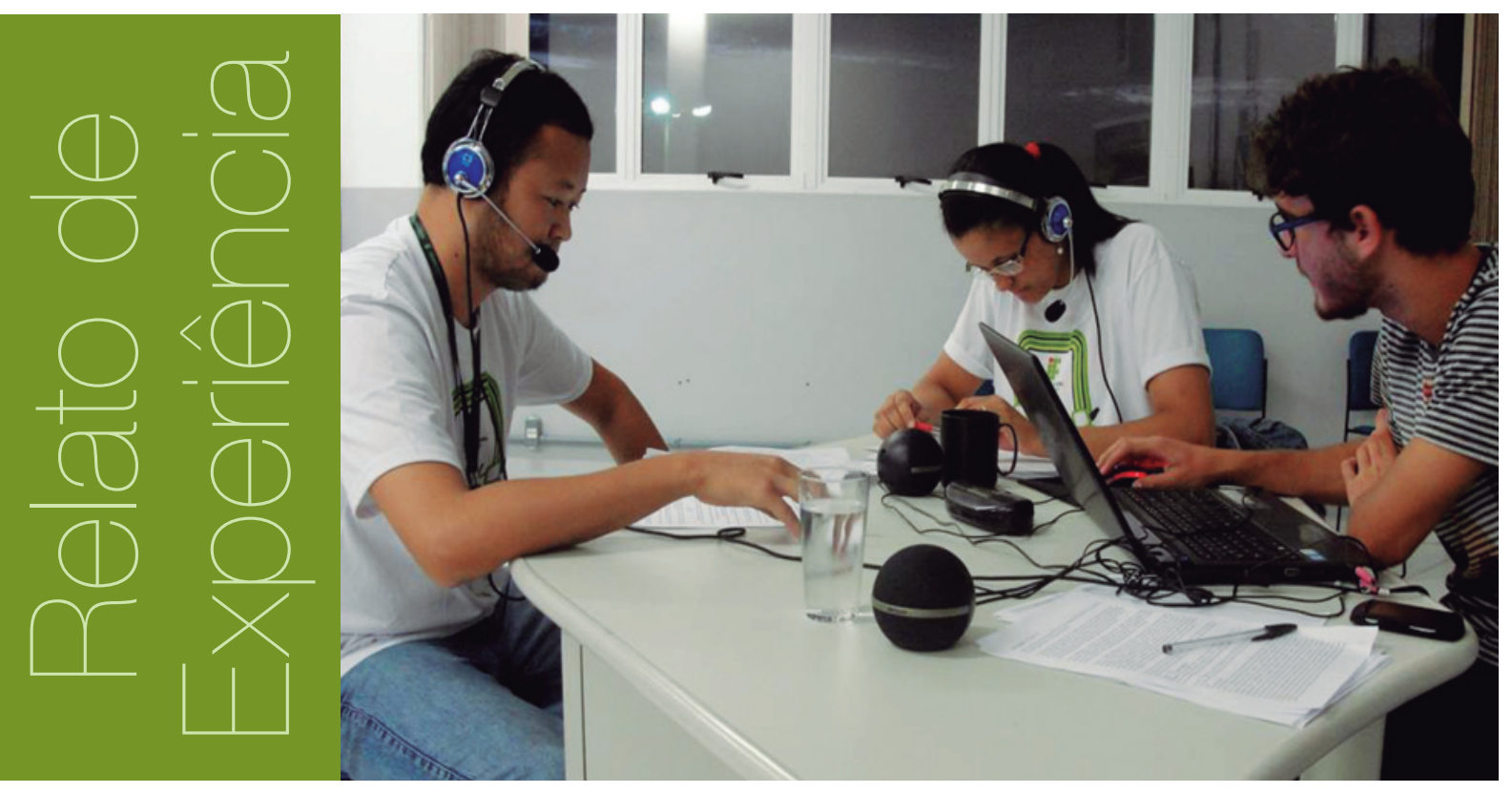

\title{
Mídia interativa e aprendizagem colaborativa: relatos de uma prática educomunicativa
}

\author{
Valdeci Reis ${ }^{-}$- valdeci.reis@ifsc.edu.br \\ Ana Paula Kuczmynda da Silveira² - ana.paula@ifsc.edu.br \\ Israel Weingartner ${ }^{3}$ - israel_wein@hotmail.com
}

\section{RESUMO}

Em função do reconhecimento de estudiosos da área de mídias em educação quanto à importância da inserção de Tecnologias da Informação e Comunicação (TIC) nos processos educativos, o presente trabalho analisa o processo de implantação da Web Rádio IFSC Câmpus Gaspar, compreendendo-o como um mecanismo que proporcionou o uso das tecnologias da comunicação na educação, a interdisciplinaridade, o aprimoramento da competência linguística oral e escrita, bem como a oportunidade de reflexão por parte daquele que produziu o conteúdo informado, envolvendo ainda 0 trabalho em equipe. A Web Rádio IFSC permitiu que o câmpus potencializasse sua comunicação com a sociedade gasparense, além de propiciar uma maior integração entre toda a comunidade acadêmica.

\section{PALAVRAS-CHAVE}

Educomunicação. Rádio educativa. Aprendizagem colaborativa.

\section{ABSTRACT}

Due to the recognition of scholars in the field of media education on the importance of integration of Information and Communication Technologies (ICT) in the educational processes, this paper analyzes the implementation of Web Radio IFSC Campus Gaspar, understanding it as a

\footnotetext{
1 Mestrando em Educação, Técnico em Educação do IFSC Câmpus Gaspar.

2 Doutora em Linguística, Professora do IFSC Câmpus Gaspar.

3 Acadêmico do Curso Técnico em Química Integrado ao Ensino Médio, Bolsista de Extensão no IFSC Câmpus Gaspar.
} 
mechanism provided that the use of communication technologies in education, interdisciplinarity, the improvement of oral and written language skills, as well as the opportunity for reflection on the part of him who produced the content informed by involving teamwork. The Web Radio IFSC allowed the campus potentiate their communication with gasparense society, and encourage greater integration of the entire academic community.

\section{KEYWORDS}

Communication. Educational radio. Collaborative learning.

\section{Introdução}

Este trabalho apresenta e discute os resultados do projeto de extensão "Web Rádio IFSC: uma proposta educativa para difundir ciência, tecnologia, inovação e cultura", desenvolvido de março a agosto de 2014 no Câmpus Gaspar do Instituto Federal de Educação, Ciência e Tecnologia de Santa Catarina.

0 projeto seguiu os pressupostos da educomunicação, área do conhecimento que busca pensar, pesquisar e trabalhar a educação formal, a informal e a não formal a partir de ecossistemas educativos. Nessa perspectiva, a comunicação deixa de ser vista como um fenômeno tão somente midiático, de função instrumental, para integrar dinâmicas formativas e planos de aprendizagem. Essa proposta inclui a consciência diante da produção de mensagens pelos veículos de comunicação tradicionais e o posicionamento perante um mundo fortemente editado pelo complexo industrial de produção simbólica. A prática educomunicativa pressupõe uma transformação radical nos processos de aprendizagem, uma renovação dos meios de aquisição do conhecimento e uma nova postura perante a vida pública e a cidadania.

0 projeto teve como objetivo geral implantar a Web Rádio IFSC Câmpus Gaspar, proporcionando o protagonismo estudantil e permitindo que os discentes explorassem as habilidades no campo da comunicação social e promovessem informação, entretenimento e interação no espaço escolar.

Os objetivos específicos foram: a) exercitar a comunicação oral, aperfeiçoando a objetividade e a clareza de exposição do pensamento; b) favorecer a convivência e o trabalho em grupo, respeitando as diferenças, os níveis de conhecimento e os ritmos de aprendizagem de cada integrante da equipe; c) aperfeiçoar a comunicação nas ações do câmpus; d) proporcionar um canal de divulgação e de produção cultural para todos os estudantes; e) consolidar o processo de ensino-aprendizagem da comunicação sob o ponto de vista linguístico, realizando um trabalho fonético intenso; f) aproximar os discentes dos diferentes meios tecnológicos e audiovisuais; e g) fomentar a educação entre os diversos agentes educativos (alunos, professores, família e a comunidade na qual a instituição está inserida).

\section{Metodologia}

A metodologia desse projeto de extensão teve como fonte de inspiração a etnografia crítica, que, no entendimento de Macedo (2006), é uma ação enraizada, ao mesmo tempo, no sujeito observador e no sujeito observado. Dessa forma, são considerados sujeitos ativos tanto os pesquisadores quanto os pesquisados, que interagem no processo de investigação. Para esse autor, uma das fontes de rigor da etnografia é o esforço incessante de analisar a realidade como ela se apresenta, com todas as suas "impurezas", ao evidenciar as contradições, os paradoxos, as ambivalências e os inacabamentos.

Ao utilizar a etnografia crítica, o extensionista deve: manter-se atento aos novos elementos que emergem durante o processo; considerar o contexto em questão; revelar a multiplicidade de dimensões presentes no objeto pesquisado; diversificar as fontes de informações; possibilitar ao participante a elaboração de "generalizações naturalísticas"; trazer para o estudo os pontos de vista conflitantes e divergentes; e utilizar um estilo mais informal de linguagem (LÜDKE; ANDRÉ, 1986, p. 18-21). 
Ainda nessa perspectiva, é muito importante o envolvimento do pesquisador e do pesquisado, formando um "corpus" (MACED0, 2006, p. 97) interessado na busca do conhecimento, que é gerado na prática participativa que a interação possibilita. 0 processo educativo se dá pela pesquisa-extensão, na medida em que se articulam o saber científico e o senso comum na busca da pertinência científica e da relevância do conhecimento produzido.

\section{Resultados}

Os meios de comunicação, quando utilizados no ambiente escolar, tornam-se maneiras de estimular nos alunos reflexões críticas diante dos discursos das mídias tradicionais (PEREIRA; COUTINHO, 2014). A Web Rádio IFSC surge com essa mesma proposta, uma vez que busca envolver toda a comunidade escolar do Câmpus Gaspar, introduzindo as tecnologias de comunicação nesse ambiente, promovendo, assim, a produção textual e a reflexão crítica dos temas a serem abordados. Nesse sentido, pode-se classificá-la como um projeto que trabalha a educomunicação e que se enquadra na comunicação alternativa.

Para Pereira e Coutinho (2014), a educominucação pode ser compreendida como os processos de desvelamento da mídia, voltados à superação do divorciamento entre o ensino e a apropriação de mensagens televisivas. Dessa forma, a educomunicação, quando aplicada no ambiente escolar em projetos como a Web Rádio IFSC, estimula o estudante a participar de novas formas de comunicação, desvencilhando-se da mídia tradicional e criando um pensamento crítico acerca da informação a ser transmitida. Dentro dessa perspectiva de educomunicação, 0 estudante estará participando de um tipo de comunicação alternativa.

A mídia alternativa é aquela que possui um compromisso com a comunicação como um bem comum e direito humano (SIMÕES, 2013; MORAES, 2013). Fernandes (2013) compreende a comunicação alternativa como uma forma de comunicação contra-hegemônica. "De forma simplória, poderíamos definir mídia alternativa como aquela que não é tradicional" (GÓES, 2007 apud COMEDIA, 1984 apud ATTON, 1999). Atualmente, com o crescente acesso da população à Internet, o número de blogs e sites com conteúdo de mídia alternativa vem aumentando, o que contribui para a democratização da informação. A Web Rádio IFSC também se inclui nesse processo, divulgando na Internet todo o conteúdo produzido pelos estudantes. Consequentemente, o projeto dessa rádio não abrange somente a comunidade escolar, mas sim a rede mundial de computadores.

Figura 1: Bolsistas e alunos discutindo a elaboração do programa de rádio "Com a Palavra os Estudantes"

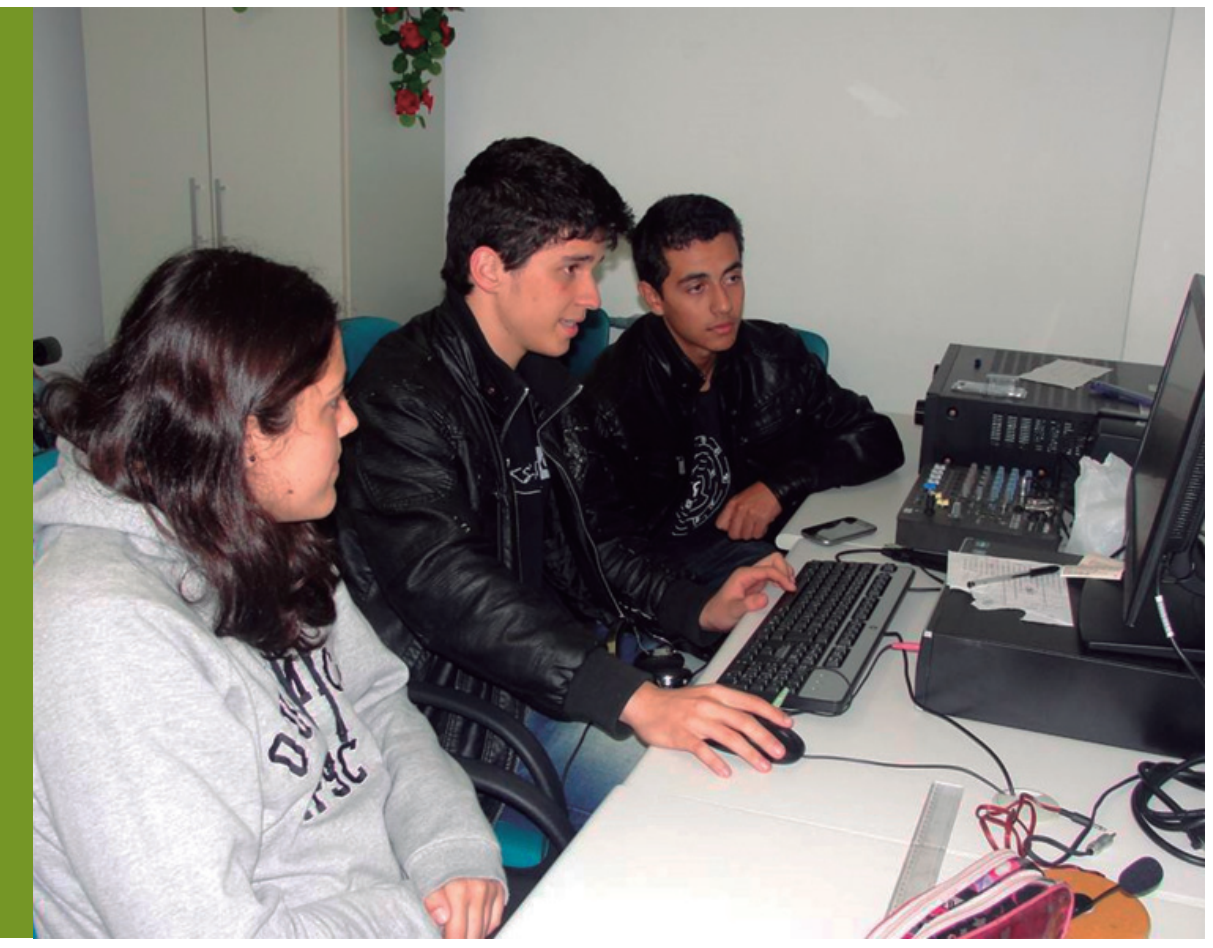


Na comunidade escolar do Câmpus Gaspar, a Web Rádio IFSC dá visibilidade aos projetos de pesquisa e extensão desenvolvidos pelos estudantes que participam da produção dos programas, elaborando a apresentação de seus trabalhos e exercendo a função de locutores. Assim, o projeto colabora para o protagonismo estudantil dentro da proposta de educomunicação e de mídias alternativas, oferecendo aos estudantes a oportunidade de produzir informação a partir do conhecimento obtido em suas pesquisas e não somente de reproduzir informações já conhecidas.

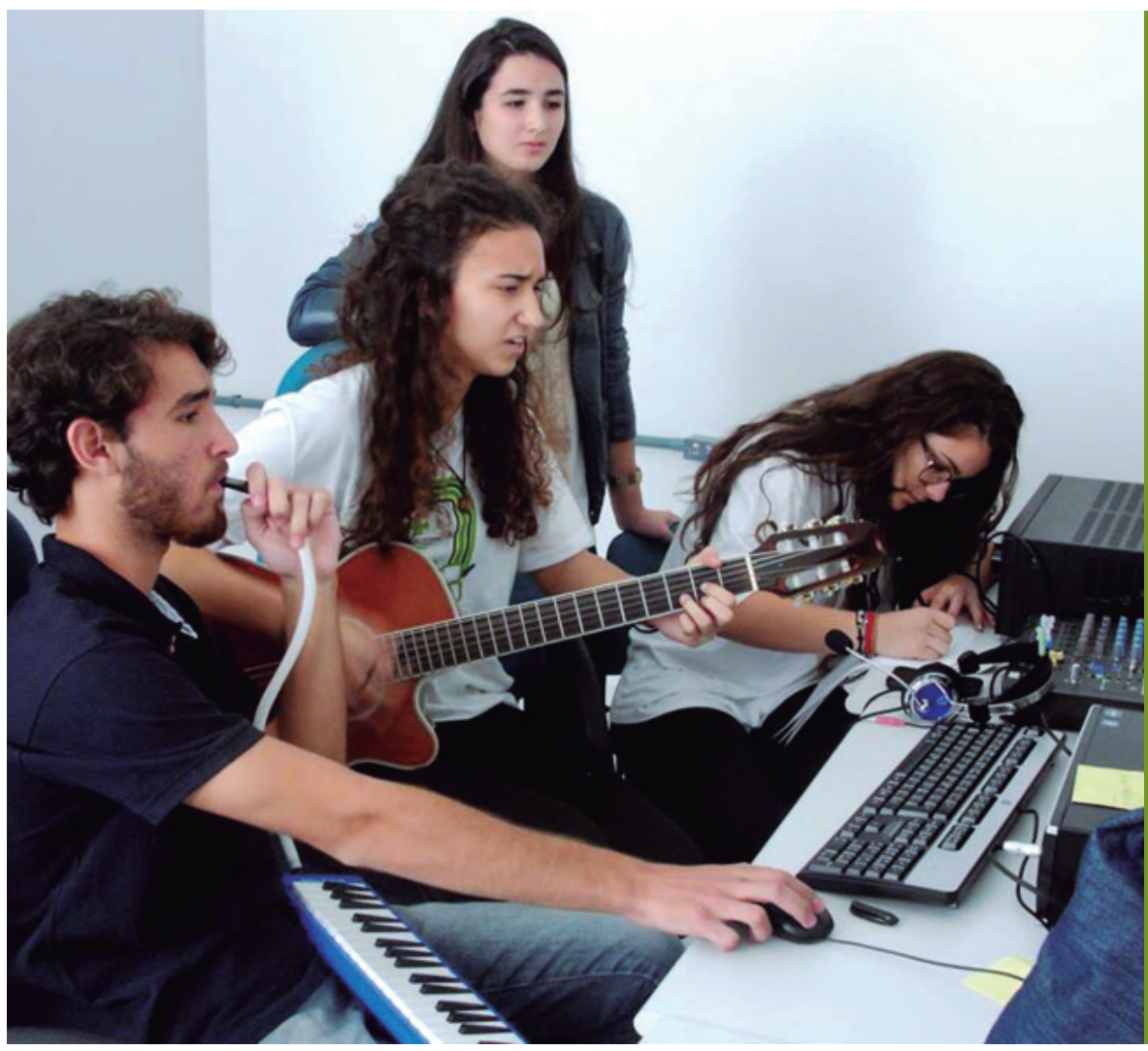

Figura 2: Alunos e jovens da comunidade de Gaspar produzindo um programa de rádio musical

Quando se trabalha com uma rádio escolar, a música está sempre presente, mas, dentro da perspectiva de educomunicação e mídia alternativa, há a necessidade de se reproduzir músicas que, além de entreter os estudantes, propiciem a reflexão acerca da ideologia de cada letra. Logo, ao apresentar programas que problematizam diversos estilos musicais, na maioria das vezes, sem espaço na mídia tradicional, o projeto da Web Rádio IFSC também participa como mídia alternativa. Além disso, essa rádio escolar traz programas que levantam discussões sobre problemas sociais emergentes na sociedade atual, cumprindo, assim, seu compromisso de transmitir suas mensagens de maneira crítica e reflexiva, envolvendo toda a comunidade escolar do Câmpus Gaspar nesse processo.

A Web Rádio IFSC toca diariamente nos espaços de convivência do Câmpus Gaspar, e todos os programas produzidos ficam disponíveis no blog http://webradioifscgaspar.blogspot.com.br/. Os principais programas são: Rhythms del Mundo, Programas Temáticos, Hashtag IFSC, Toque Ambiental, Papo Filosófico, Laboratório do Rock, La ventana La Canción, Estúdio Interativo, Music Break, Com a Palavra os Estudantes, Especial MPB, Entrevistas, Sarau, Os Livros do Mês, Café Pop, Papo Reto e Café com a Reitora.

A equipe da Web Rádio IFSC também conta com um espaço na rádio comunitária 98,3, Vila Nova FM (Vale do Itajaí). Diariamente, os bolsistas e extensionistas vinculados ao projeto produzem e apresentam o programa de rádio Educação em Debate, que vai ao ar de segunda a sexta-feira, das 11:30 às 12:00. Trata-se da ação de maior impacto junto à sociedade do Vale do Itajaí. Nesse programa, são discutidas as ações de ensino, pesquisa e extensão do Câmpus Gaspar. 


\section{Referências bibliográficas}

EVANGELISTA, Ana Paula Souto. Meios de comunicação tradicionais $\mathbf{X}$ mídias alternativas, como está a qualidade da informação que chega à população?. Natal: UFRN, 2008.

FERNANDES, Vivian de Oliveira Neves. Panorama da mídia alternativa no Brasil e na América Latina. São Paulo: USP, 2013.

GÓES, Laércio Torres de. Contra-hegemonia e Internet: Gramsci e a Mídia Alternativa dos Movimentos Sociais na Web. Salvador: UFBA, 2007.

HAUSER, Vanessa. GAGLIARDI, André. 0 espaço da mídia alternativa nas sociedades democráticas contemporâneas e seu papel na formação do pensamento crítico. ljuí: UNIJU, S/D.

LUDKE, Menga; ANDRÉ, Marli Eliza Dalmazo Afonso. Pesquisa em educação: abordagens qualitativas. São Paulo: EPU, 1986.

MACEDO, Roberto Sidnei. A etnopesquisa crítica e multirreferencial nas ciências humanas e na educação. Salvador: EDUFBA, 2006.

PEREIRA, Caroline Marino; COUTINHO, lluska. A educomunicação como leitura crítica da mídia: práticas e conceitos nas produções acadêmicas apresentadas nos congressos da Intercom, entre 2011 e 2013. Vila Velha: INTERCOM, 2014. 